\title{
Central Coast growers' trust in water quality regulatory process needs rebuilding
}

\author{
A 2015 survey of growers showed their trust of the regional water board had decreased since 2006, \\ even though there had been more frequent communication.
}

by Ann Drevno

$\mathrm{M}$ any, if not most, water bodies in Central Coast agricultural areas are severely degraded due to chemical inputs. Nitrates have become a critical problem for groundwater contamination and drinking water supplies (Harter et al. 2012). Additionally, agricultural pesticides (e.g., historically organophosphates, currently pyrethroids) are a major source of regional toxicity (Anderson et al. 2003; Anderson et al. 2006; Anderson et al. 2010; Anderson et al. 2011; Hunt et al. 1999; Phillips et al. 2012; Phillips et al. 2006). Sediments are another top water pollutant in the area.

Improving water quality in agricultural areas is contingent on a variety of factors, including landowners' and growers' decisions on land use and farming practices. The choice to adopt protection measures on farms can be influenced by real estate markets, government policies, and individual motivations (Ryan et al. 2003), as well as by the existence of trusting relationships between growers and regulatory agencies (Leach and Sabatier 2005; Lubell 2007).

Anecdotal evidence suggests that issues of trust and communication are especially germane in the Central Coast region. Regulatory relationships there appear to be at a critical juncture. Local farming organizations have voiced their concerns over the decreasing collaboration between regulators and growers over the past decade.

In discussions leading up to the California Legislature's 2002 decision to end agriculture's

\section{Abstract}

Growing evidence of agricultural water pollution in California's Central Coast even after the implementation of tough water quality regulations has increased the pressure on regional stakeholders. Previous research has shown that collaborative relationships between growers and regulators can motivate growers to make management decisions that benefit the environment. However, informal evidence suggested trust might have been eroding between growers and the Central Coast Regional Water Quality Control Board (CCRWQCB, the regulator) since 2004, the year the first legislation went into effect. Using a survey conducted in 2015, interviews and in-depth document review, this study assesses growers' trust of and communication with other agricultural groups and water quality regulatory agencies, specifically CCRWQCB. Survey results were compared to results of the same survey sent out in 2006. Results corroborate other research - growers' trust of most regional agricultural groups was closely correlated with frequency of communication. However, growers' trust of CCRWQCB did not correspond to the relatively high contact frequency and had declined since 2006 . The literature on rebuilding trust suggests ways forward for CCRWQCB.

exemptions from waste discharge requirements, agricultural interests recognized that the water quality problem was not going to fade. That recognition motivated the Farm Bureau, a trusted agricultural organization, to become part of the conversations and solutions (farm advisor, personal communication, February 2013). The political context at the time - mounting
Online: https://doi.org/10.3733/ ca.2018a0015

Agricultural pollution affects many water bodies on California's Central Coast and has prompted regulatory action. This article examines the perspectives of Central Coast growers on water quality issues and on the many groups involved in water quality regulation and management, including agricultural groups and the Central Coast Regional Water Quality Control Board. 
The Central Coast Regional Water Quality Control Board is one of nine statewide; each water quality control board issues permits and enforces requirements at the local level. Map of California regional water quality control boards adapted from California Water Boards brochure (revised May 2013).

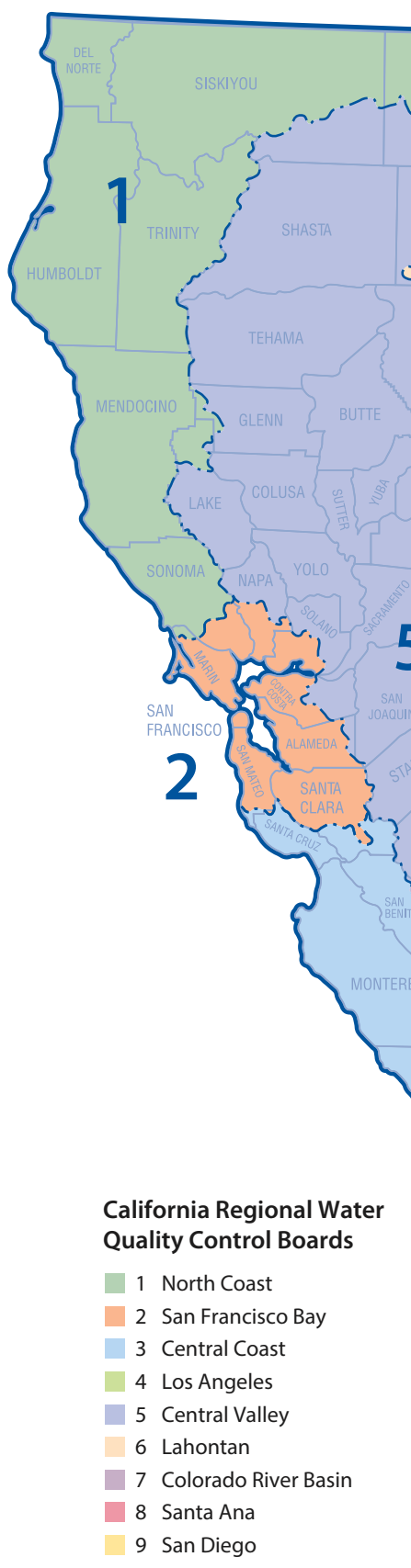

cases of polluted drinking water, the passage of Senate Bill 390, which reasserted pressure on regional water boards to take more responsibility for comprehensive water control, and public frustration with polluted waterways - set the stage for a unique regulatory process in which agricultural interests sought to support water regulations and become more involved (Kranz 2004).

As one UC Cooperative Extension (UCCE) advisor described the situation (personal communication, February 2013), the Farm Bureau "became instrumental in calming [the growers] down, deciding to be proactive, and working with others to convince the farming community that [water quality control measures] were worth investing in."

In 2004, the Farm Bureau reiterated these collaborative sentiments, stating that although

"the [new water quality mandates] weren't perfect," the Central Coast Regional Water Quality Control Board (CCRWQCB) had taken a "constructive approach" (Kranz 2004). Eight years later, the extent of perceived collaboration among agricultural stakeholders leading up to the 2012 Agricultural Waiver dramatically shifted. Instead of the Farm Bureau lauding the regulatory process as "constructive," it called it "flawed" and lacking in collaboration and participation (Campbell 2012).

Although the Farm Bureau's perspective may shed light on an important trend occurring in the Central Coast regulatory process, no research has yet examined growers' opinions on trust, water quality issues and the regulatory process over time and the resultant policy implications. My goal was to survey hundreds of growers and ground-truth the reported changes in opinions and relationship patterns over a 9-year period, from 2006 to 2015 .

\section{Rigorous regulatory changes}

Each of California's nine regional water quality control boards (or regional boards) has the authority to regulate water quality at a local level. Included in a regional board's jurisdiction is the right to waive the discharge permits so that an industry that releases pollutants into state waters, including agriculture, need not apply for a permit. After the passage of Senate Bill 390 in 1999, however, regional boards issuing waivers to agriculture had to attach conditions (e.g., any mandated requirements, best management practices, monitoring requirements) to the waivers and renew or update those mandates at least every 5 years.

In 2004, CCRWQCB passed its first Conditional Waiver of Waste Discharge from Irrigated Lands (the 2004 Agricultural Waiver). The conditions required growers to enroll in the agricultural waiver, complete 15 hours of water quality education, prepare a farm management plan, implement water quality improvement practices and complete individual or cooperative water quality monitoring. When the 2004 Agricultural Waiver expired in July 2009, substantial data from the cooperative monitoring program and scientific studies demonstrated that water bodies in the region continued to be severely impaired from agricultural runoff. Because the Central Coast Water Board did not have a quorum to adopt a new agricultural waiver, the order was extended with some modifications until July 2010. With the board still at an impasse, the 2004 waiver was extended three more times (July 2010, March 2011 and September 2011).

After nearly 3 years of negotiation, on Mar. 15, 2012, CCRWQCB passed a new waiver. The updated and more comprehensive 2012 Agricultural Waiver placed

farms in one of three tiers, based on their risk to water quality (Tier 1 being the lowest risk and

Tier 3 the highest), and imposed requirements for each tier. For Tier 1 and 2 farms, the requirements were similar to those in the 2004 order with two notable additions: groundwater monitoring (all tiers) and total nitrogen application reporting (for some Tier 2 and Tier 3 farms). Tier 3 farms, on the other hand, had to comply with several new rigorous provisions, including individual discharge monitoring and reporting.

A third agricultural waiver (or Ag Order 3.0) was adopted on 
Mar. 8, 2017, and will be in effect for only 3 years, as it was intended to be an interim order. The most significant changes are more extensive groundwater monitoring and nitrogen application reporting.

Across the region, a variety of third-party organizations have arisen to assist CCRWQCB in controlling water pollution and to help growers comply with the conditions of the agricultural waivers. These organizations have become deeply embedded in the regional governance and agricultural support networks. For example, Central Coast Water Quality Preservation, Inc., or Preservation, Inc., manages the cooperative monitoring program for growers enrolled in the agricultural waiver; the California Department of Pesticide Regulation (DPR) delivers statewide pesticide regulatory programs, and county agricultural commissioners' offices regulate pesticide use on a local level, among other duties; local Farm Bureau offices collaborate with other agricultural organizations to advocate and provide services for local growers; and UCCE, U.S. Department of Agriculture (USDA) Natural Resources Conservation Service, and local California resource conservation districts have established programs that provide technical and financial assistance to help growers integrate best management practices into farming systems.

Each organization has different relationships with regional growers, colored by historical interactions and its institutional goals. My study tracked growers' trust with these organizations, how much they valued the information and communication with the organizations, as well as how their views of them changed over time and in response to the first two agricultural waivers.

\section{Motivations to change behavior}

Growers' behavioral decisions to alter farming practices in favor of the environment have been widely researched (Beedell and Rehman 2000; Knowler and Bradshaw 2007 Prokopy et al. 2008). Prior studies in the field of agricultural economics have developed models to predict growers' decision-making, many of which assume that they will maximize profits over other objectives (Willock et al. 1999). However, behavioral economists, political scientists, social psychologists and other social scientists have demonstrated how cultural and psychological concerns can also heavily motivate growers' decisions to change their behavior (Chouinard et al. 2008; Leach and Sabatier 2005; Mzoughi 2011). Dozens of case studies and several meta-analyses synthesizing these works (Knowler and Bradshaw 2007; Prokopy et al. 2008) cite a wide range of environmental factors influencing growers' choice to adopt best management practices. These include a motivation to show others their environmental commitment (Mzoughi 2011), a desire to protect the environment (Greiner and Gregg 2011), a strong attachment to the land (Ryan et al. 2003) and good stewardship (Brodt et al. 2004; Ryan et al. 2003).

Of interest to my research is a growing body of work in the fields of political science and environmental policy that demonstrates how trust between stakeholders, including regulators and regulated groups, can impact growers' decisions, and change their views over time. Trust has been reported as a pivotal factor in solving natural resource conflicts, especially common resources (Cox et al. 2009; Ostrom et al. 1999; Ostrom and Walker 2003; Rudeen et al. 2012). Given its weight in environmental policy processes, researchers have endeavored to uncover ways in which trusting relationships are cultivated as well as how they degrade.

Communication can greatly influence trust. According to Leach and Sabatier (2005), "The strength of each interpersonal relationship ought to increase with the frequency of contact and with the cumulative number of interactions over time." Research also shows that it is not only the contact frequency but also the type of contact that matters. For example, the history of interactions (Lubell 2007) and of agreements or disagreements (Leach and Sabatier 2005) can inform trust.

Whether the communication is in-person or long distance also plays a role. Ostrom and her colleagues (1994) found that face-to-face communication is a promising means of fostering trust. Others have found that a lack of face-to-face contact could be disadvantageous; for example, institutional distance between growers and regulatory agencies, could hinder trust building (Lubell 2007). Communication among growers is also important: Lubell and Fulton (2008) showed that growers' relationships with their agricultural community, or "diffusion networks," such as with other growers, local outreach and education agencies, and neighbors, were pivotal in growers' decisions to adopt best management practices for water quality.

Agricultural water quality regulation in California's Central Coast is laden with contentious issues of trust, collaboration and stakeholder involvement (Drevno 2016).

\section{Two grower surveys}

This study uses data from two public opinion surveys. The first survey was conducted by UC Davis Professor Mark Lubell and UCCE agent Mary Bianchi in 2006, which was 2 years after the first agricultural waiver was adopted. The survey was mailed to 1,994 growers in Santa Barbara and southern San Luis Obispo counties. The list of growers was assembled from UCCE educational classes. A total of 454 completed surveys were received. This first survey employed Dillman's (2000) total design method, which includes an introduction letter followed by two waves of survey packages and reminder postcards.

I sent out the second survey in 2015 , which was 2 years after the second agricultural waiver was implemented. (The second waiver was passed in 2012, but because of a deferral, or stay, it was not put into effect until 2013.) The second survey was approved for exemption from IRB review by UC Santa Cruz. To make accurate comparisons, the 2015 survey used the same survey techniques and prompts as the 2006 survey.

Because the list of 2006 survey recipients was not publicly available, the second survey was sent to all growers enrolled in the 2012 Agricultural Waiver available through the electronic Notice of Intent. The second survey was conducted through an email survey portal. After duplicate email addresses, erroneous email addresses, and email addresses of growers no longer farming were removed, the survey distribution list was comprised of 1,089 growers across the Central Coast region. A total of 230 completed surveys were received. While the respondents in the 2015 survey were not the same set of growers as in the 2006 survey, all respondents were growers in the region under the same regulatory system.

A paired $t$-test was used to examine the differences in attitudes between 2006 and 2015 survey responses, as well as other factors that may have changed over time. Pearson's correlation tests were employed in hypothesizing a close relationship between trust of a water quality agency and the information value received from that agency.

To complement the results from the surveys and further trace the evolution of agricultural stakeholder narratives between 2006 and 2015, I completed a detailed set of qualitative interviews with key actors (growers and agency officials) knowledgeable about the 
agricultural water quality regulatory process. I also analyzed secondary data - CCRWQCB meeting minutes, policy reports, newspaper and magazine articles and judicial proceedings.

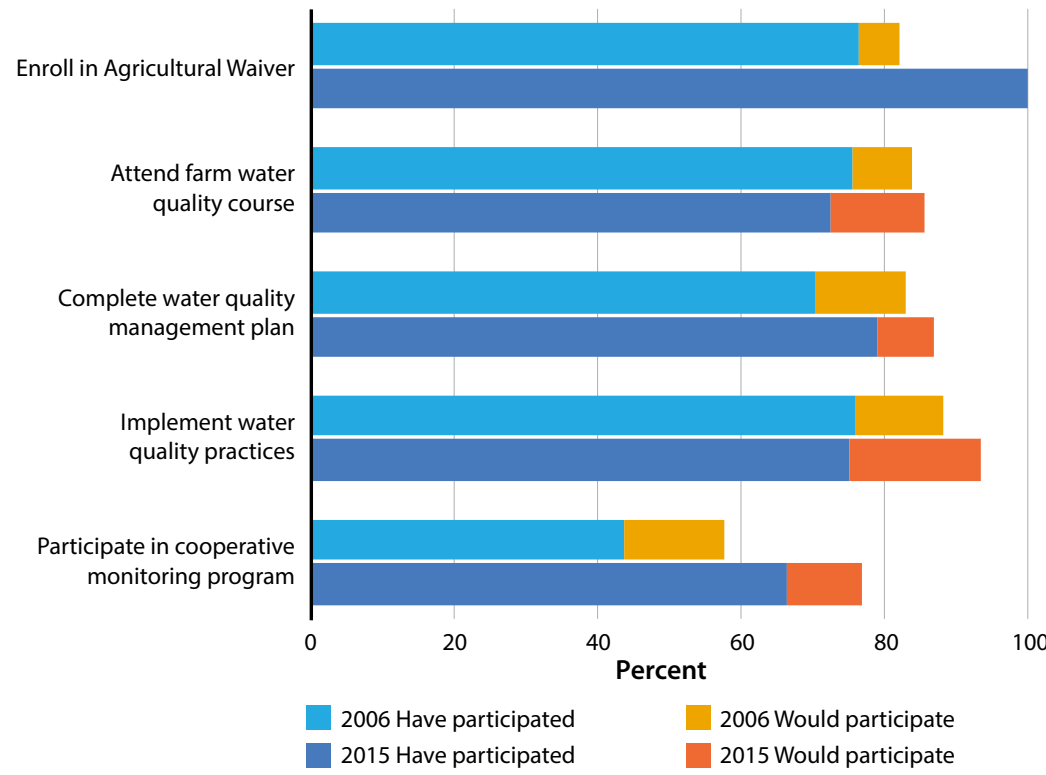

FIG. 1. Types of water quality management activities growers in the Central Coast had already adopted or would be interested in adopting, as self-reported in 2006 and 2015 surveys.

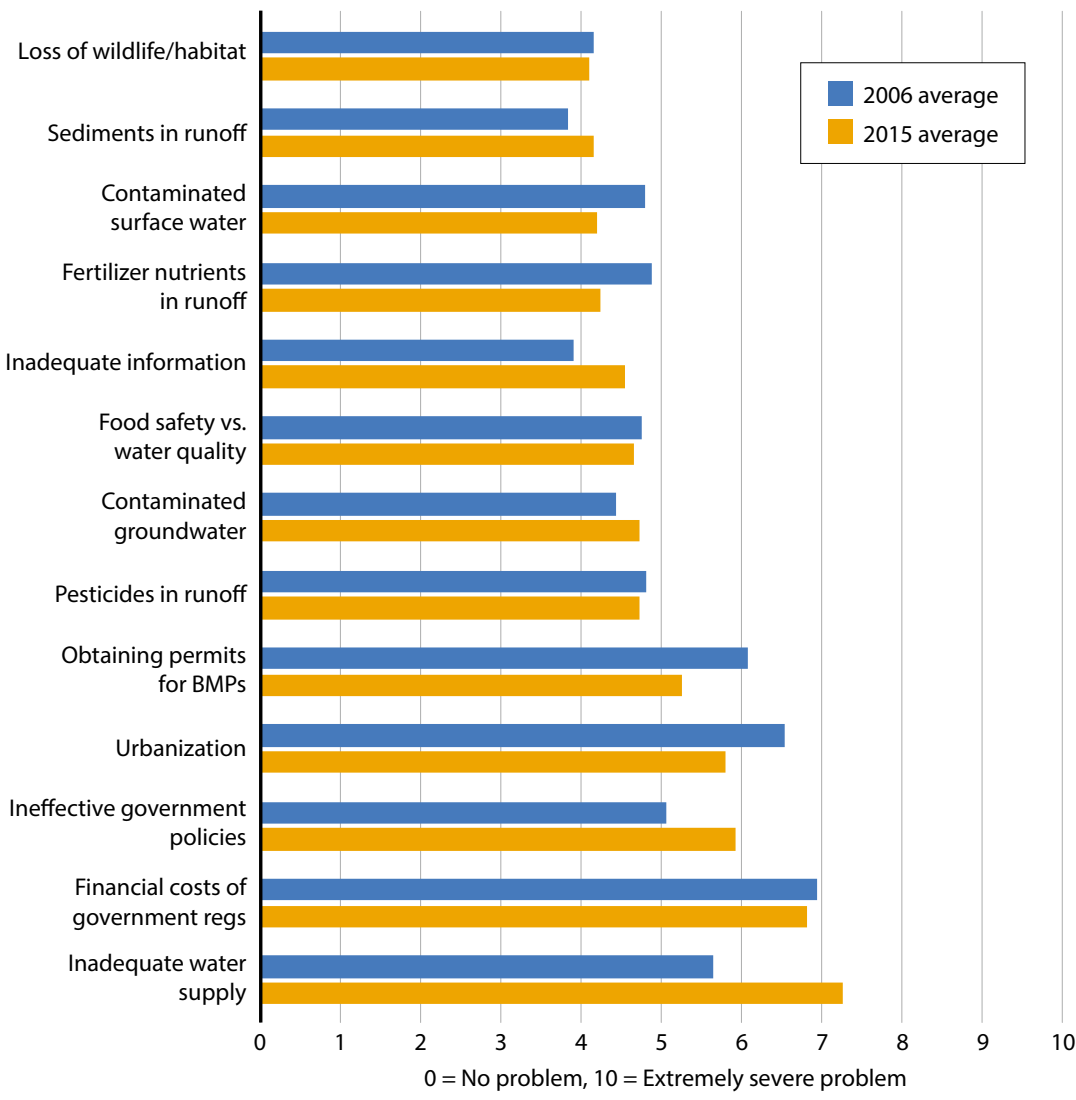

FIG. 2. Growers' opinions on the seriousness of various water quality issues, in 2006 and 2015.

\section{Growers self-report high scores}

The first set of questions in the survey asked growers what types of water quality management activities they had already participated in or would be interested in participating in. Growers self-reported very high scores (fig. 1). One interesting result was the discrepancy in reported participation in the cooperative monitoring program compared to the actual participation numbers recorded by the program (found as part of the review of secondary data). The reported participation of over $95 \%$ of all growers was substantially lower than the program documentation numbers. The most plausible explanation is that enrolled growers simply forgot that they had enrolled or did not realize they had done so, especially in 2006, when the cooperative monitoring program and monitoring provisions were new to growers.

\section{Pollution not the biggest issue}

A second set of questions asked survey participants to share their opinions of water quality issues (fig. 2). Eight issues placed an average score of 5 or less, meaning growers thought these issues ranked closer to being "no problem" than "an extremely severe problem." These included pollution from pesticides, fertilizers and sediments and contamination of groundwater and surface water. Of these, surface water pollution and fertilizer pollution significantly dropped in importance to growers over the 9-year period.

Despite participants perceiving these five water quality issues to be less severe than other problems, academics, scientists and regulators often cite these issues as the most problematic sources of water quality contamination (Anderson et al. 2003; Anderson et al. 2010; CCRWQCB 2011a; Harter et al. 2012). For example, in a review of scientific data, CCRWQCB staff "found that many of the same areas that showed serious contamination from agricultural pollutants 5 years ago are still seriously contaminated" and that "staff does not believe there is improvement in nitrate concentrations in areas that are most heavily impacted" (CCRWQCB 2011a). Additionally, scientific studies published during this period showed increasing evidence of ambient toxicity in the Central Coast region due to pesticides (Anderson et al. 2006; Anderson et al. 2011; Hunt et al. 1999).

Growers identified as the most serious regional water quality problems the issues more directly impacting their farm viability and management practices. In 2015, during a historic 4-year drought, inadequate water supply was unsurprisingly growers' top concern; in the 2006 survey it ranked as the fourth most serious concern. Three of the five water quality issues most worrying growers were related to the regulatory process - the financial costs of regulations, ineffective government policies and obtaining permits for best management practices. Ineffective government regulations rose from being the fifth greatest concern in 2006 to the third greatest concern in 2015, which supports 
the Farm Bureau's account of amplified frustration over the regulatory process.

\section{Ecological issues and fairness matter}

The third set of questions aimed to assess growers' motivations and cultural values in their water quality decision-making (fig. 3). More than $75 \%$ of respondents from both surveys agreed with the following statements:

- Growers have a duty to protect the land.

- Growers' knowledge is important for policymaking.

- I am complying with water quality regulations.

- Protecting the environment is as important as economic viability.

- Most growers are implementing water quality practices.

- Government decisions should consider as many different interests as possible.

These results indicate that growers generally believe they are protecting water quality, that they have a duty to do so and that environmental goals are just as important as profitability. They corroborate the results of previous studies that demonstrated ecological and moral concerns mattered in growers' decision-making and motivations were not exclusively profit driven (Chouinard et al. 2008; Mzoughi 2011).

One issue that more growers disagreed with in 2015 was that "the management practices requirements of the Ag Waiver are fair to agricultural producers." As Drevno (2016) states in her paper on the Central Coast agricultural water quality regulatory process, fairness was a hotly contested issue in the 2012 Agricultural Waiver negotiations. The issue of equity arose in several areas of the negotiations, spanning the types of best management practices required to the cost and unequal burdens of tiered mandates.

\section{Trust and communication}

The final series of questions asked growers about their trust of and communication with other agricultural groups and water quality agencies and about the value of information they received from those organizations (fig. 4). In both years, environmental groups were the least trusted and least communicated with; other growers were the most communicated with but not necessarily the most trusted.

Survey data show a very close relationship between information value and trust. Results from a Pearson's correlation test found a strong positive relationship between the two variables; the coefficients ( $r$ score) were close to a perfect positive relationship $(r=1)$, varying only between 0.80 and 0.99 .

There also appeared to be a close positive relationship between amount of communication, trust and information value (fig. 4). These results support the body of literature on the connection between trust and contact frequency, but they show a few exceptions. Despite more communication, growers reported a dip in trust of a few organizations, including CCRWQCB and Preservation, Inc. The regional board is located at a sufficient physical distance from growers in the northern part of the region: over 170 miles for growers in southern Santa Clara County and northern Santa Cruz County, which could hinder face-to-face communication. Another possible explanation might be that the values and interests of growers are different than those of regulatory agencies (Leach and Sabatier 2005; Lubell 2007).

\section{Growers generally believe they are protecting water quality, that they have a duty to do so and that environmental goals are just as important as profitability.}

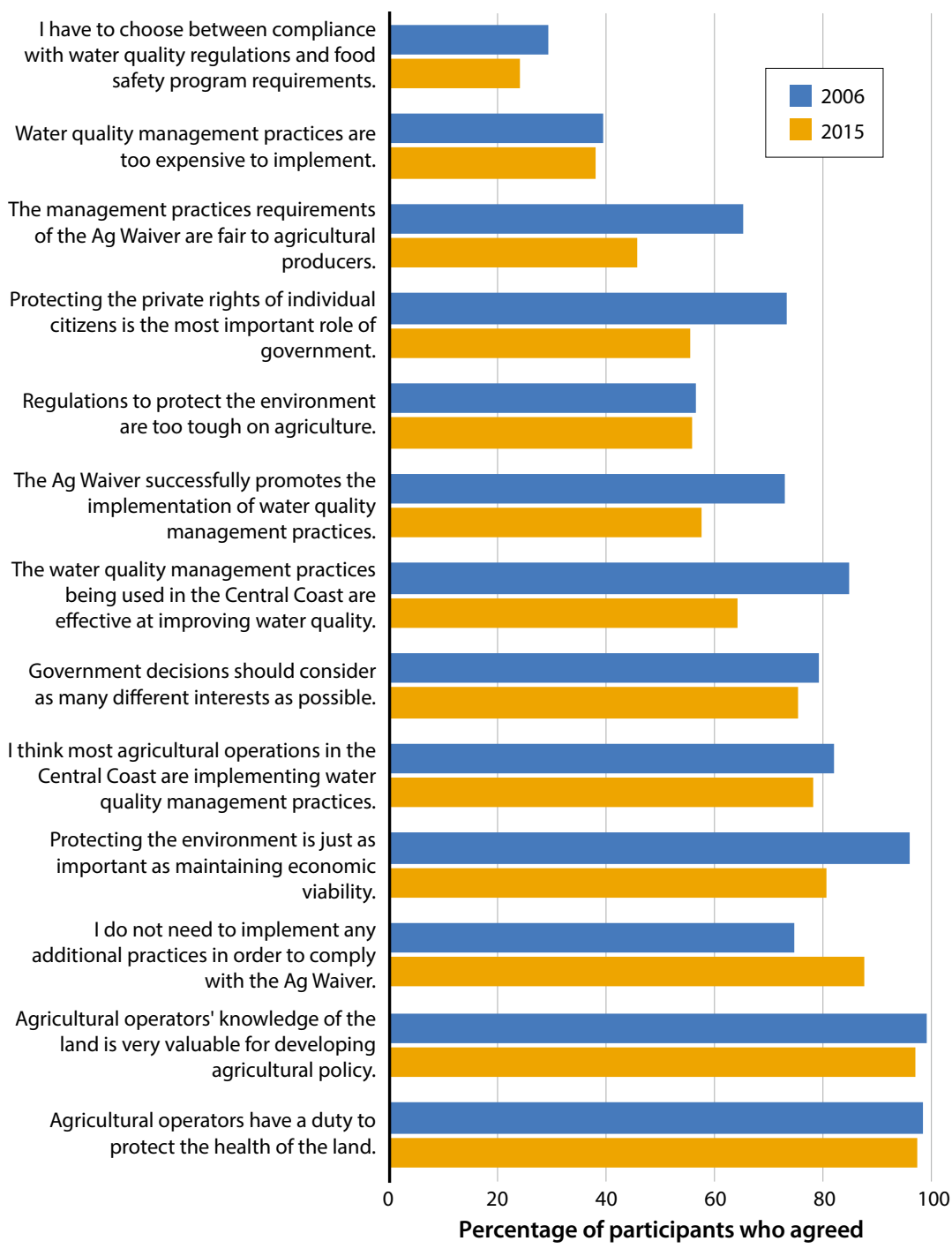

FIG. 3. Growers' opinions on land stewardship and water quality regulation issues. 
2006

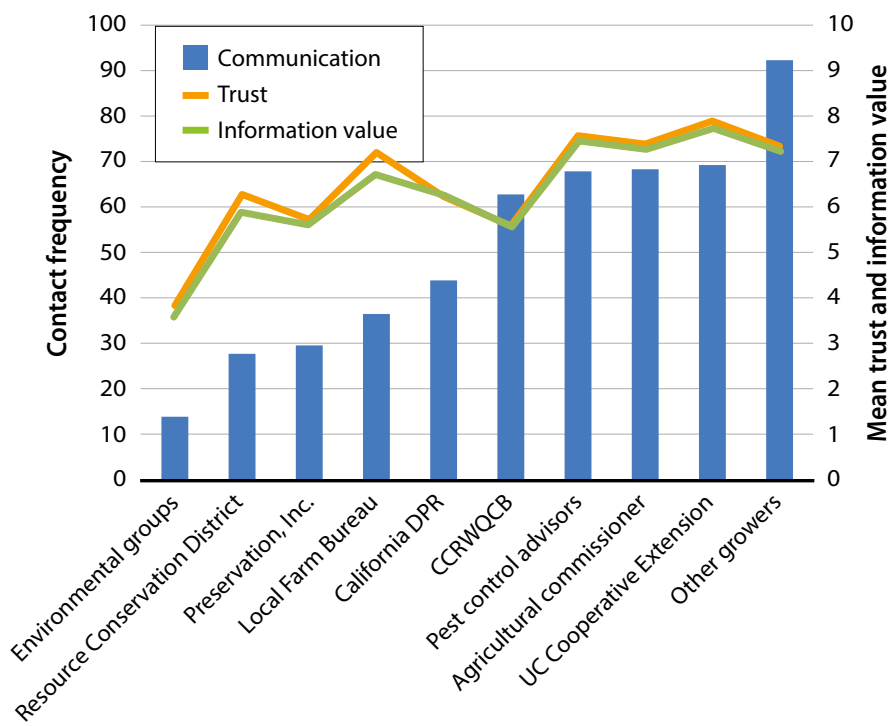

2015

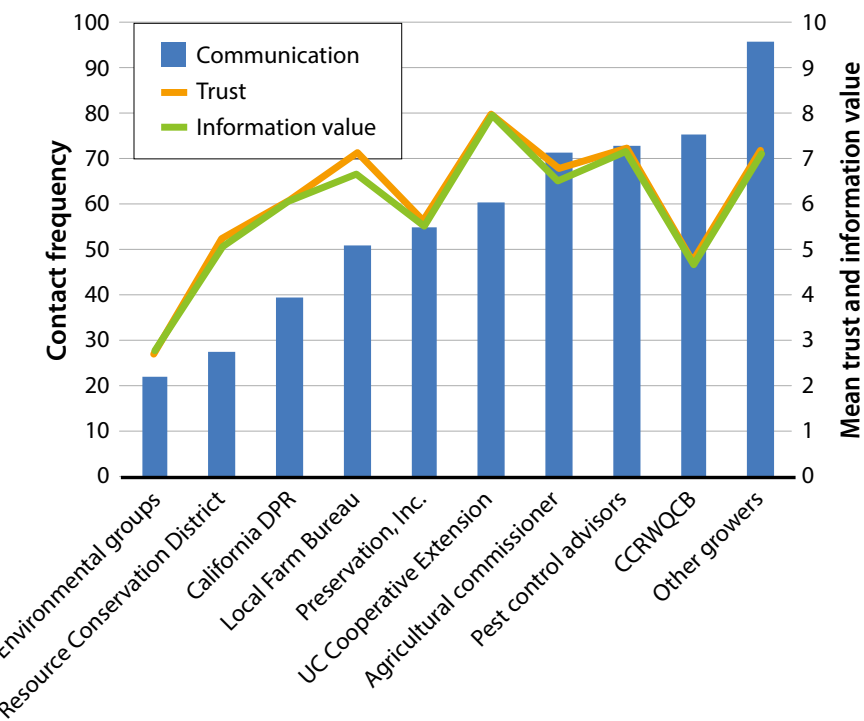

FIG. 4. Growers' trust of, contact frequency with, and perceived value of the information from water quality management organizations in the Central Coast Region, 2006 and 2015.

The biggest dip in trust despite more frequent communication was with CCRWQCB, the main regulatory agency in the region. Lubell (2007) explains the phenomenon of distrust that may occur between their perceived adversaries: "Farmers tend to categorize policy organizations according to their perceived policy interests: regulatory agencies are viewed as serving environmentalists, while local agricultural agencies and private agricultural organizations are seen as serving the farmer. Thus, growers view regulatory agencies as less trustworthy and local agricultural agencies as more trustworthy."

Different policy interests could also help explain the low scores on trust of environmental groups; growers

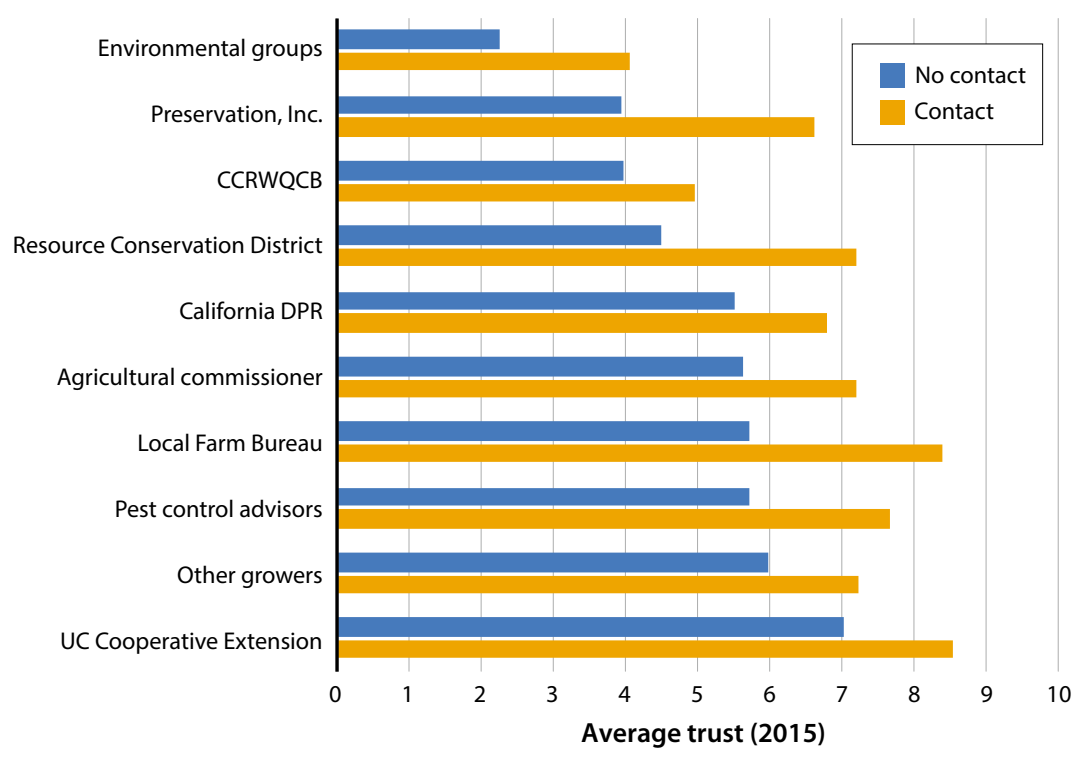

FIG. 5. Growers' trust of various water quality management organizations and contacts with those organizations, 2015. scored their trust of those groups at 3.6 out of 10 in 2006, and 2.8 in 2015.

The survey results on trust of and contact with nonregulatory agencies confirm a strong relationship between the two variables. The 2015 results generally show that there was a significant improvement in the amount of trust when a grower had contact with an organization compared to when a grower had no contact (fig. 5). But with CCRWQCB, as described earlier, and with other growers, trust did not significantly improve with contact.

To test the observation of trust decreasing the study compared mean trust of the various organizations for the two surveyed years (fig. 6). The decrease in trust of CCRWQCB between 2006 and 2015 was significant $(t$ score $=0.002$ ); mean scores were 5.60 in 2006 and 4.75 in 2015.

Finally, the study assessed for correlation a subset of 2015 responses regarding opinions on required water quality management practices and a subset of 2015 responses related to trust of CCRWQCB. Findings suggest that growers' trust of CCRWQCB is associated with their opinions on required water quality practices (fig. 7). Trust of CCRWQCB was greater among growers who agreed or strongly agreed with statements related to the fairness, effectiveness and success of water management practices mandated in the agricultural waivers. Trust of CCRWQCB was lower among growers who disagreed with those statements.

\section{Eroding trust, future fix}

Although growers' frequency of contact with CCRWQCB did not increase their trust of it, it does not follow that growers' communication with or the information they receive from regulatory agencies is disadvantageous. Rather, more research is needed into the 
types of communication used by CCRWQCB, how their communication has changed over time and how the CCRWQCB's communication might influence relationships with the regulated group.

That there was a correlation between growers' trust of CCRWQCB in 2015 and their opinions on its water quality management decisons cannot confirm causation - that trust leads to a convergence of beliefs, or a convergence of beliefs leads to trust; however, prior studies suggest the latter (Leach and Sabatier 2005). To build trust between two rival political actors is complicated, especially because core beliefs can be culturally embedded or shaped by historical events. However, it is possible.

The trust process is best begun by achieving agreement on, at very least, empirical issues with sound evidence. Leach and Sabatier (2005) offer a few ways to undertake the process: (1) a "professional forum" exposing scientific evidence from competing coalitions mediated by a neutral facilitator (p. 464), (2) starting negotiations with a period of joint fact-finding and consensus building on the basic dimensions of the problems (p. 499) or (3) pursuing empathy-building exercises such as field trips (p. 499).

While encouraging accounts of a collaborative relationship between growers and CCRWQCB during the 2004 Agricultural Waiver negotiations are difficult to substantiate from the 2006 survey responses, results from the 2015 survey and agriculture testimonies confirm that what rapport remained after 2004 was markedly soured during subsequent negotiations. There was a significant drop in trust by 2015 , and in the survey growers reported that they were increasingly frustrated by the policy process, the majority agreeing that regulations were "unfair" and "too tough."

"Trust ought to be correlated with the length, depth, and recency of past collaboration" (Leach and Sabatier 2005), and only 9 years prior, growers and CCRWQCB had joined efforts to pen the first ever regulatory program for agricultural water quality in the Central Coast. So why did trust degrade after 2004, and what lessons might be learned for future agricultural waiver negotiations?

A fatalistic explanation is that the decline in trust was inevitable. Comfortable with the 2004 provisions that they had collaboratively designed, growers became frustrated by increasing mandates. Unavoidably, the 2004 Agricultural Waiver was going to be made tougher - scientists, the state, and the public demanded that CCRWQCB act on the growing evidence that water quality was not improving.

A second explanation is that the approach CCRWQCB staff took during the drafting of the second agricultural waiver tainted relations. During the drafting of the 2004 Agricultural Waiver, staff took a collaborative and educational approach, slowly easing the agricultural industry into water quality regulations. Whereas for the second agricultural waiver, CCRWQCB negotiators took a more centralized approach and came out of the gates strong, proposing the very tough 2010 Draft Order that categorized farms into tiers with coupled mandates, brought individual monitoring into the fold for the first time and required certain blanket provisions for all farms. Several agricultural interests claimed the new regulatory program was "the most rigorous in the state" (CCRWQCB 2011b). Although the new waiver was significantly watered down by the time it was ratified, the process leading up to it had greatly strained rapport, and opened a rift between growers and CCRWQCB that would be difficult to restore.

Many growers and agricultural stakeholders highlighted above all else their disappointment in how the negotiations were handled, emphasizing the process itself more than particular mandates. The Santa Barbara Farm Bureau wrote that its members supported the 2004 Agricultural Waiver because it "focused on collaboration" and was "based on a good faith effort from both the agricultural community as well as [the Regional] Board"; however, they were "extremely disappointed" by the stakeholder participation process for the updated

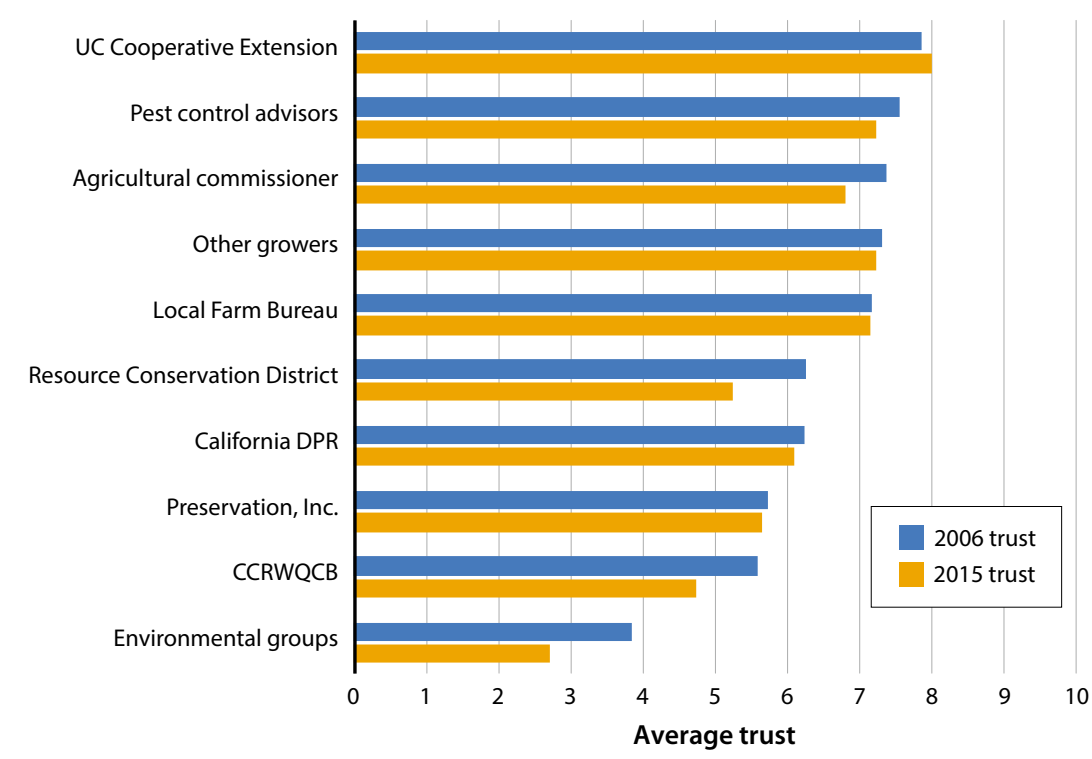

FIG. 6. Growers' trust of different water quality organizations in 2006 and 2015.

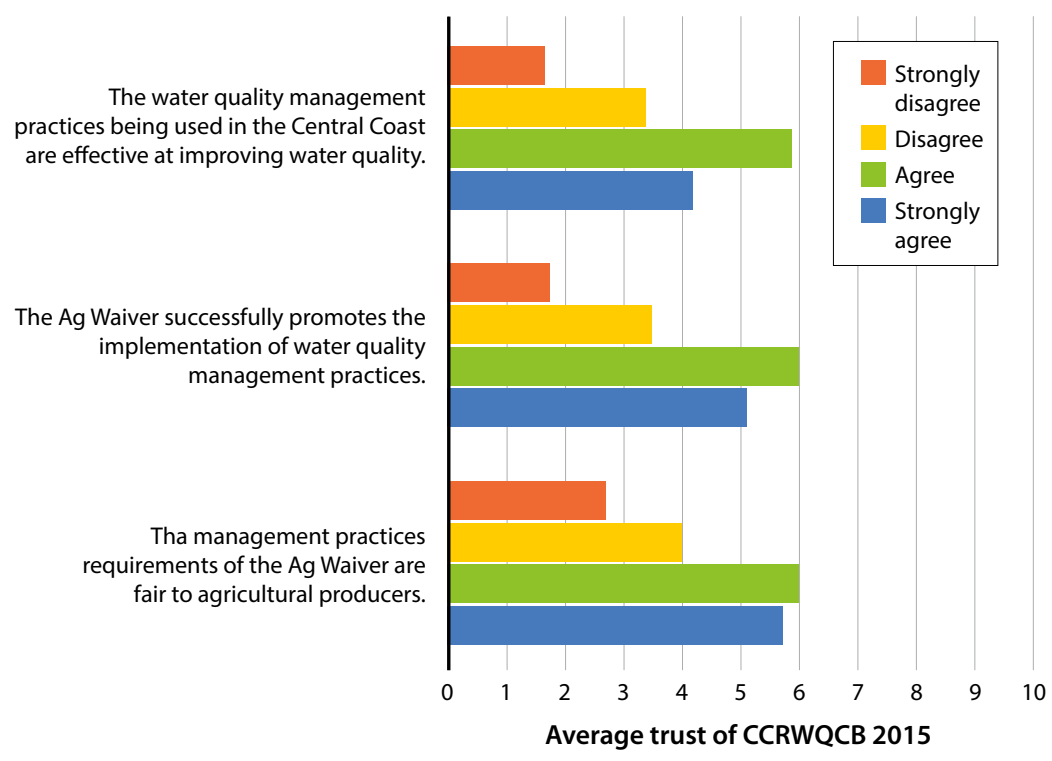

FIG. 7. Correlation of growers' 2015 responses regarding opinions on required water quality management practices and their trust of CCRWQCB. 
waiver, calling it a "failed" attempt due to staff members' "reluctance to collaborate."

Another statement that more pointedly aimed at issues of declining trust and collaboration between growers and CCRWQCB came from the Santa Barbara County Flower and Nursery Growers Association: "It appears that [CCRWQCB] staff is proposing to squander the spirit of cooperation that has been so assiduously developed over the years, and to destroy the degree of trust between the private and public sector that has been diligently promoted over these same years. This arrogant, and heavy-handed, jack-boot approach will utterly destroy any hope of cooperation or trust from the private sector."

Sacramento County Superior Judge Frawley recently (Superior Court of California 2015) ruled that the 2012 Agricultural Waiver did little more than the 2004 Agricultural Waiver in improving water quality and needed to be greatly strengthened. If CCRWQCB did not improve water quality through its new structure and mandates and it soured relationships with growers along the way, what can be learned from that? Could the CCRWQCB have generated a more collaborative negotiation process while improving water quality?

These questions are beyond the scope of this article; however, what is clear is that water quality must improve. Consequently, CCRWQCB should invest in rebuilding its important relationships with growers as it proceeds through the stakeholder collaboration processes for the next agricultural waiver. To begin to rebuild trust, agricultural representatives and CCRWQCB members might sit down and review together existing empirical, scientific studies on Central Coast water pollution, and, at the very least, come to a consensus regarding the state of regional water quality and the sources of pollution.

CCRWQCB may find it useful to have a third-party agency review how it has previously communicated with growers and suggest strategies to restructure future negotiation techniques. The third-party agency should be respected by growers, scientists and regulators. Growers' perception of unfairness in the water quality regulations needs to be addressed, but that's the most difficult task of all - to weigh growers' perceived fairness with more effective pollution control measures. CA

A. Drevno is National Science Foundation Postdoctoral Fellow, Santa Clara University. I would like to thank survey respondents and interviewees, and Dr. Mark Lubell and UCCE agent Mary Bianchi for their 2006 survey on which this research is based. The second round of surveys for this study received nonfinancial endorsements from four regional agricultural organizations - the Monterey County Farm Bureau, the Agriculture and Land Based Training Association (ALBA), University of California Cooperative Extension (UCCE), and Agricultural Water Quality Alliance - and many people from these organizations provided valuable feedback. I would like to thank my dissertation advisor, Daniel Press, whose insights and guidance greatly enhanced this research. My thanks to Executive Editor Jim Downing and Associate Editor Mark Lubell, and to the two anonymous reviewers for their comments and critiques on my manuscript. This project was supported by the National Science Foundation's Graduate Research Fellowship Program and Career-Life Balance Grant. Any opinions, findings and recommendations expressed in this material are those of the author and do not necessarily reflect the views of the National Science Foundation.

\section{References}

Anderson BS, Hunt JW, Phillips BM, et al. 2003. Integrated assessment of the impacts of agricultural drainwater in the Salinas River (California, USA). Environ Pollut 124(3):523-32.

Anderson BS, Phillips BM, Hunt JW, et al. 2006. Evidence of pesticide impacts in the Santa Maria River watershed, California, USA. Environ Toxicol Chem 25(4):1160-70.

Anderson BS, Phillips BM, Hunt JW, et al. 2010. Watershed-Scale Evaluation of Agricultural BMP Effectiveness in Protecting Critical Coastal Habitats: Final Report on the Status of Three Central California Estuaries. UC Davis, Granite Canyon and US Geological Survey. Grant Report for the Central Coast Water Board.

Anderson B, Phillips B, Hunt $J$, et al. 2011. Pesticide and toxicity reduction using an integrated vegetated treatment system. Environ Toxicol Chem 30(5):1036-43.

Beedell JDC, Rehman T. 2000 Explaining farmers' conservation behaviour: Why do farmers behave the way they do? J Environ Manage 57(3):165-76.
Brodt S, Klonsky K, Tourte L, et al. 2004. Influence of farm man agement style on adoption of biologically integrated farming practices in California. Renew Agr Food Syst 19(04):237-47.

Campbell K. 2012. Central Coast: State Water Board issues partial stay of new regulation. AgAlert, Sept 5.

CCRWQCB. 2011 a. Water Quality Conditions in the Central Coast Region Related to Agricultural Discharges.

CCRWQCB. 2011 b. March 17 Meeting Minutes. www.waterboards.ca.gov/centralcoast// board_info/agendas/2011/ march/Item_14/march_17 transcript_condensed.pdf Chouinard HH, Paterson T, Wandschneider PR, Ohler AM. 2008. Will farmers trade profits for stewardship? Heterogeneous motivations for farm practice selection. Land Econ 84(1):66-82.

Cox JC, Ostrom E, Walker JM, et al. 2009. Trust in private and common property experiments. Southern Econ J 75(4):957-75. Dillman DA. 2000. Mail and Internet Surveys: The Tailored Design Method (vol 2). New York: Wiley.

Drevno A. 2016. Governing water quality in California's Central Coast: The case of the conditional agricultural waiver. J Sci Policy Governance 8(1).
Greiner R, Gregg D. 2011. Farmers' intrinsic motivations, barriers to the adoption of conservation practices and effectiveness of policy instruments: Empirical evidence from northern Australia. Land Use Policy 28(1):257-65.

Harter T, Lund J, Darber J, et al. 2012. Addressing Nitrate in California's Drinking Water. Center for Watershed Sciences, UC Davis.

Hunt JW, Anderson BS, Phillips BM, et al. 1999. Patterns of aquatic toxicity in an agriculturally dominated coastal watershed in California. Agr Ecosyst Environ 75(1):75-91.

Knowler D, Bradshaw B. 2007. Farmers' adoption of conservation agriculture: A review and synthesis of recent research. Food Policy 32(1):25-48 Kranz D. 2004. Environmental recommendations gain FB support. AgAlert, Sept 22.

Leach WD, Sabatier PA. 2005. To trust an adversary: Integrating rational and psychological models of collaborative policymaking. Am Polit Sci Rev 99(04):491-503.

Lubell M. 2007. Familiarity breeds trust: Collective action in a policy domain. J Polit 69(1):237-50.
Lubell M, Fulton A. 2008. Local policy networks and agricultural watershed management. J Publ Adm Res Theor 18(4):673-96. Mzoughi N. 2011. Farmers' adoption of integrated crop protection and organic farming Do moral and social concerns matter? Ecol Econ 70(8):153645.

Ostrom E, Burger J, Field CB, et al. 1999. Revisiting the commons: Local lessons, global challenges. Science 284(5412):278-82.

Ostrom E, Gardner R, Walker J. 1994. Rules, Games, and Com mon-Pool Resources. Ann Arbor: University of Michigan Press.

Ostrom E, Walker J (eds.). 2003. Trust and Reciprocity: Interdisciplinary Lessons for Experimental Research. New York: Russell Sage Foundation.

Phillips BM, Anderson BS, Hunt JW, et al. 2006. Solid-phase sediment toxicity identification evaluation in an agricultural stream. Environ Toxicol Chem 25(6):1671-6.

Phillips BM, Anderson BS, Hunt JW, et al. 2012. Pyre throid and organophosphate pesticide-associated toxicity in two coastal watersheds

(California, USA). Environ Toxicol Chem 31(7):1595-603.
Prokopy LS, Floress K, KlotthorWeinkauf D, Baumgart-Getz A. 2008. Determinants of agricultural best management practice adoption: Evidence from the literature. J Soil Water Conserv 63(5):300-11.

Rudeen AK, Fernandez-Gimenez ME, Thompson JL, Meiman P. 2012. Perceptions of success and the question of consensus in natural resource collaboration: Lessons from an inactive collaborative group. Soc Natur Resour 25(10):1012-27.

Ryan RL, Erickson DL, De Young R. 2003. Farmers' motivations for adopting conservation practices along riparian zones in a Midwestern agricultural watershed. J Environ Plann Man 46(1):19-37.

Superior Court of California, County of Sacramento. 2015 Monterey Coastkeeper, The Otter Project, PCFFA, Environmental Justice Coalition for Water, Santa Barbara Channelkeeper, Sportfishing Protection Alliance v. California State Water Resources Control Board (SWRCB). Case Number: 342012-80001324.

Willock J, Deary IJ, EdwardsJones $\mathrm{G}$, et al. 1999. The role of attitudes and objectives in farmer decision-making: Business and environmentally oriented behavior in Scotland. J Agr Econ 50(2):286-303. 